\title{
Stress-Strain Law for Confined Concrete with Hardening or Softening Behavior
}

\author{
Piero Colajanni, ${ }^{1}$ Maurizio Papia, ${ }^{2}$ and Nino Spinella ${ }^{1}$ \\ ${ }^{1}$ Dipartimento di Ingegneria Civile, Informatica, Edile, Ambientale e Matematica Applicata, Università di Messina, Contrada di Dio, \\ Villaggio Sant'Agata, 98166 Messina, Italy \\ ${ }^{2}$ Dipartimento di Ingegneria Civile, Ambientale, Aerospaziale e dei Materiali (DICAM), Università di Palermo, Viale delle Scienze, \\ 90128 Palermo, Italy
}

Correspondence should be addressed to Nino Spinella; nspinella@unime.it

Received 7 March 2013; Accepted 8 May 2013

Academic Editor: Halil Sezen

Copyright (C) 2013 Piero Colajanni et al. This is an open access article distributed under the Creative Commons Attribution License, which permits unrestricted use, distribution, and reproduction in any medium, provided the original work is properly cited.

\begin{abstract}
This paper provides a new general stress-strain law for concrete confined by steel, fiber reinforced polymer (FRP), or fiber reinforced cementitious matrix (FRCM), obtained by a suitable modification of the well-known Sargin's curve for steel confined concrete. The proposed law is able to reproduce stress-strain curve of any shape, having both hardening or softening behavior, by using a single closed-form simple algebraic expression with constant coefficients. The coefficients are defined on the basis of the stress and the tangent modulus of the confined concrete in three characteristic points of the curve, thus being related to physical meaningful parameters. It will be shown that if the values of the parameters of the law are deduced from experimental tests, the model is able to accurately reproduce the experimental curve. If they are evaluated on the basis of an analysis-oriented model, the proposed model provides a handy equivalent design model.
\end{abstract}

\section{Introduction}

Upgrading of reinforced concrete structures in seismic areas is often required due to the need for a higher performance and safety level or material deterioration. Increment of deformation capacity of the structure in critical regions, where large plastic deformations are expected, is one of the most efficient strategies in this field. For reinforced concrete (RC) elements, the simple application of fiber reinforced polymer (FRP) embedded in epoxy resin and/or fiber reinforced cementitious matrix (FRCM) can dramatically enhance strength and ductility of concrete columns. Jacketing over the entire length of the element by FRP or FRCM wraps is often preferred, due to the favourable properties of this retrofitting methodology: extremely low weight-to-strength ratio, easy application, minimal change in the behaviour of the structure, and protection and prevention of corrosion. In order to evaluate the effects of such a retrofitting strategy on the seismic behavior of the structure, stress-strain relationship of confined concrete is needed to evaluate the momentcurvature response of the elements [1].
When steel transverse reinforcement as a confining system is utilized, as soon as the transversal stress on the concrete reaches the cracking limit, the lateral strain suddenly grows and the confining steel hoops yield. From this point, a nearly constant confining pressure is applied to the column concrete core, and the concrete behaves as an active confined material [2]. Therefore, the stress-strain relationship of a steel-confined concrete member is characterized by a steep increasing branch up to the yielding of the transversal reinforcements, followed by a softening branch, with a slope related to the effectiveness of the confinement.

FRP jackets, as opposed to steel hoops, have an elastic behavior up to failure and exert a monotonic increasing confining action. Usually, the stiffness and strength of the confining jacket is sufficient to ensure the absence of softening behavior (heavily confined concrete), and the stress-strain curves feature an ascending bilinear shape. Such behavior has been detected in most of the experimental tests, performed on specimens of small scale. In these cases, the thickness of a single or few layers of FRP is able to confer enough stiffness to 


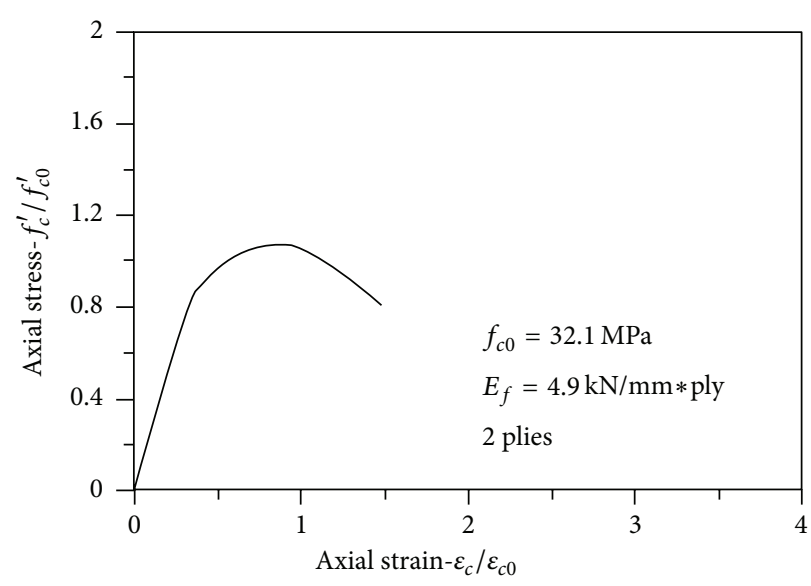

(a)

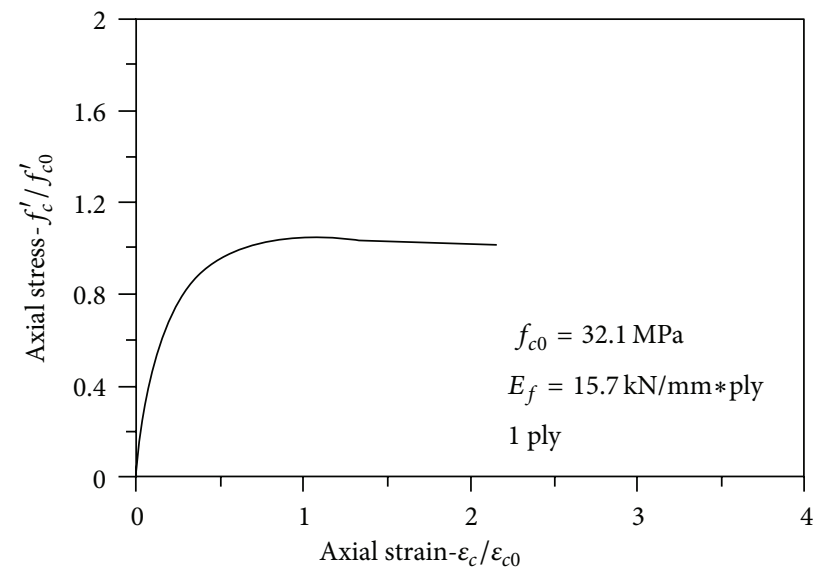

(b)

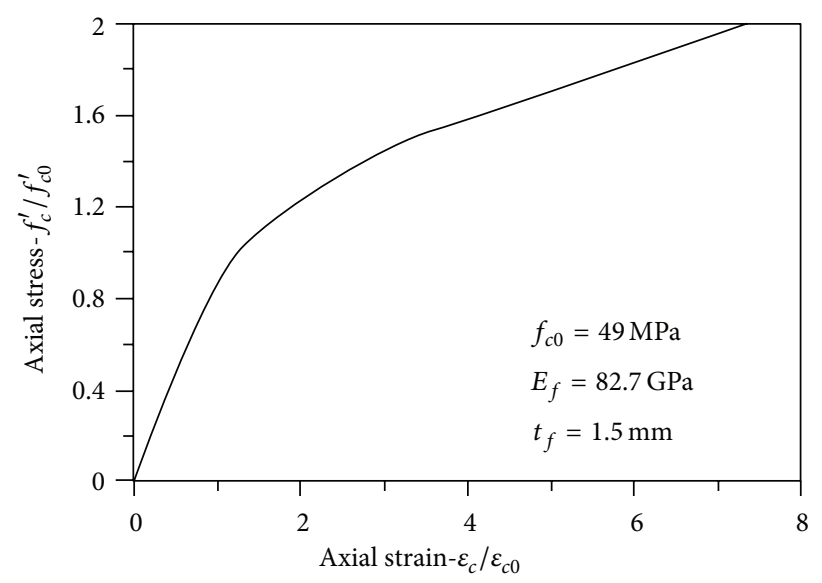

(c)

FIGURE 1: Experimental stress-strain relationships with different confinement levels: (a) Harries and Kharel [8]; (b) Harries and Kharel [8]; (c) Shahawy et al. [7].

the wrapping to avoid a softening behavior. Lam and Teng [3] have stressed that for large structural elements, such as piers of bridges, or when fibers with low strength and low elasticity modulus are utilized (such as glass or aramid fibers), or when elements with rectangular cross section are considered, the lateral pressure cannot always provide enough confinement to ensure a hardening behavior. Elements confined with FRCM often exhibit a flat or a descending postpeak branch, due to the progressive cracking of the binding mortar in the range of large deformation [4-6].

Thus, depending on the confinement level three different behaviors in the large strain range have been observed in experimental tests: a decreasing branch with ultimate strength lower than the strength of the unconfined concrete (very lightly confined concrete); a decreasing branch with gently slope, sometimes terminated with a branch with a positive stiffness recovering, having in both cases the ultimate strength greater than the strength of the unconfined concrete (lightly confined concrete); an increasing branch up to failure (heavily confined concrete).

In Figure 1, the three shapes of the stress-strain curve obtained in experimental tests $[7,8]$ are shown.
In practical application, a reliable design of FRP jackets requires that the constitutive behavior of the FRP-confined concrete is accurately modeled. Since the last decade, many constitutive models have been proposed for the behavior of RC member wrapped with FRP jacket, and many reviews are given in the literature [9-11]. The models are classified in several ways: theoretical (or mechanical) models, derived by the analysis of the mechanism by which the confining pressure is activated, are diversified from analytical and semi-empirical models, that reproduce the results of tests by analytical expressions, with numerical coefficients deduced by regression analyses [9]; general models, that are able to reproduce stress-strain curve of any shape, are diversified by prefixed-shape models, that are able to reproduce only the simplified shape of the curve (i.e., bilinear models) or are not able to reproduce both softening and hardening behavior [12]; Lam and Teng [3] diversified design-oriented models and analysis-oriented models; in the first category, stressstrain curves are given in closed-form expressions, while in the second, the behavior of confined concrete is predicted by using incremental iterative procedures. Most of the analysisoriented constitutive laws are well based on mechanical 
models and are effective in reproducing stress-strain curves of any shape, but the use of incremental or iterative procedures make the models suitable for use in computer analysis only, such as nonlinear finite element analysis (NLFEA). By contrast, most of the design-oriented models available in the literature are able to reproduce only the hardening behavior of the heavily confined concrete [10] or are obtained by two different analytical relations in the low and high strain field.

This paper provides a new general design-oriented stressstrain law, obtained by a suitable modification of the wellknown Sargin curve [13] for steel confined concrete. The proposed law is able to reproduce stress-strain curve of any shape, having both hardening or softening behavior, by using a single closed-form simple algebraic expression with constant coefficients. The coefficients are defined on the basis of the stress and the tangent modulus of the confined concrete in three characteristic points of the curve, thus being related to physical meaningful parameters. It will be shown that if the values of the parameters of the model are deduced from experimental tests, the model is able to accurately reproduce the experimental curve. If they are evaluated on the basis of an analysis-oriented model, the proposed law provides a handy equivalent design model.

\section{Models for Concrete Confined by FRP Jacket}

Several reviews on models for FRP-confined concrete are available in the literature [9-11]. Most of the models have been formulated by generalization of an existing stressstrain relationship derived for steel-confined concrete. Three expressions have been used most frequently: the general expression proposed by Sargin [13], the four parameter stressstrain curve proposed by Richard and Abbot [14], and the Mander et al. model [15], that had been derived on the basis of Popovics' relation [16] for confined concrete.

Sargin's curve, that will be discussed in the next section, has been modified by Ahmad et al. [17] for modeling the behavior of concrete spirally confined by fiberglass filament. The tests conducted by the cited authors showed a descending branch of the stress-strain curve in the postpeak region, due to the small stiffness and strength of the confining filament. Therefore, this model conserves the main limitation of the Sargin model that is not able to reproduce the characteristic hardening behavior of the FRP heavily confined concrete. Other researches had proposed a modified version of Sargin's curve for modeling the stress-strain in the low strain range and different equations in the high strain range: Toutanji [18] and Saafi et al. [19] used separate equations for axial stress and strain both of which are functions of the lateral strain; Miyauchi et al. [20], Lillistone and Jolly [21], and Jin et al. [22] used a straight line to represent the second portion of the stress-strain curve. The major drawbacks of these models are the use of two different analytical expressions for modeling the entire range of the constitutive curve and the ineffectiveness for lightly confined element, in modeling the possible stiffness recovering for high strain values.

In order to obtain a single relation for modeling stressstrain curve with an almost linear behavior in the high strain range, Richard and Abbot [14] proposed to describe the elastic-plastic constitutive law by the following four parameter curve:

$$
\sigma=\frac{\left(E_{1}-E_{2}\right) \varepsilon}{\left\{1+\left|\left(E_{1}-E_{2}\right) \varepsilon / f_{0}\right|^{n}\right\}^{1 / n}}+E_{2} \varepsilon
$$

where $\sigma$ and $\varepsilon$ are the current stress and strain, $f_{0}$ is the stress at the intersection of the linear branch of the curve in the high strain range with the reference $\sigma$ axis, $E_{1}$ and $E_{2}$ are the initial and the plastic module, respectively, and $n$ is a shape parameter controlling the transition from the two portions of the curve. The models proposed by Samaan et al. [23], Xiao and $\mathrm{Wu}$ [24], and Moran and Pantelides [25] are the most popular ones that were derived on the basis of (1). The formulation of Samaan et al. [23], calibrated with the results of tests on 30 small diameter concrete-filled FRP tubes, is not able to represent post-peck decreasing stress-strain curve, while the formulation of Moran and Pantelides [25] requires an incremental iterative procedure and thus does not possess the necessary simplicity for design application.

Several models, able to represent stress-strain curve of different shapes, have been obtained by using the following well-known stress-strain relationship for unconfined concrete proposed by Popovics [16]:

$$
\frac{f_{c}^{\prime}}{f_{c 0}^{\prime}}=\frac{x r}{r-1+x^{r}}
$$

where $f_{c 0}^{\prime}$ is the strength at the corresponding strain $\varepsilon_{c 0}$ for the unconfined concrete, $r$ is the parameter that controls the nonlinear descending branch, and $x=\varepsilon_{c} / \varepsilon_{c 0}$ is the normalized strain. Equation (2) has been utilized by Mander et al. [15] for modeling the behavior of steel-confined concrete, assuming that the confinement pressure has the constant value given by the yielded steel transversal reinforcements, and evaluating the correspondent peak strength of the confined concrete by regression of experimental results. Saadatmanesh et al. [12] were the first that extended to FRP-confined concrete members the Mander's model [15], still assuming a constant value of the confinement pressure given by the FRP jacket at the rupture condition. Spoelstra and Monti [26] recognized that, for FRP materials that apply on the concrete core, a continuously increasing pressure, Mander's model [15] can be extended only if the continuous increment of the confining pressure is considered in the model; this goal has been obtained by regarding the resulting stress-strain curve as a curve crossing a family of Mander's curves, each one pertaining to the level of confining pressure corresponding to the current lateral strain. Fam and Rizkalla [27] and Harries and Kharel [28] also used Mander's model [15], evaluating the lateral strain by different tools: the first ones proposed an equation representing the change of secant Poisson's ratio with confining pressure; the latter proposed an empirical relationship based on the results of experimental tests, modifying also the exponent in (2) by a curve-fitting factor. These two models, as well as the Spoelstra and Monti [27] one, require also an incremental iterative procedure for evaluation of the stress-strain curve. 


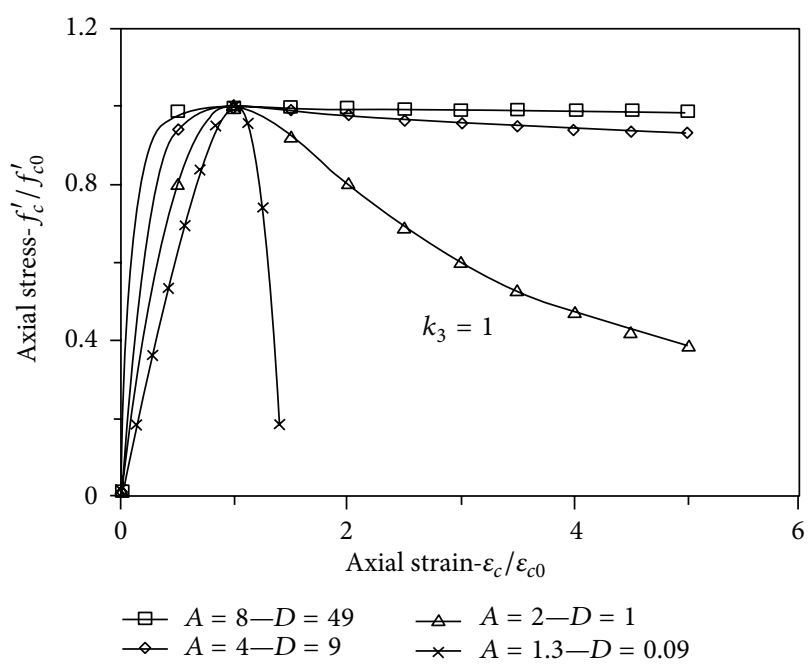

(a)

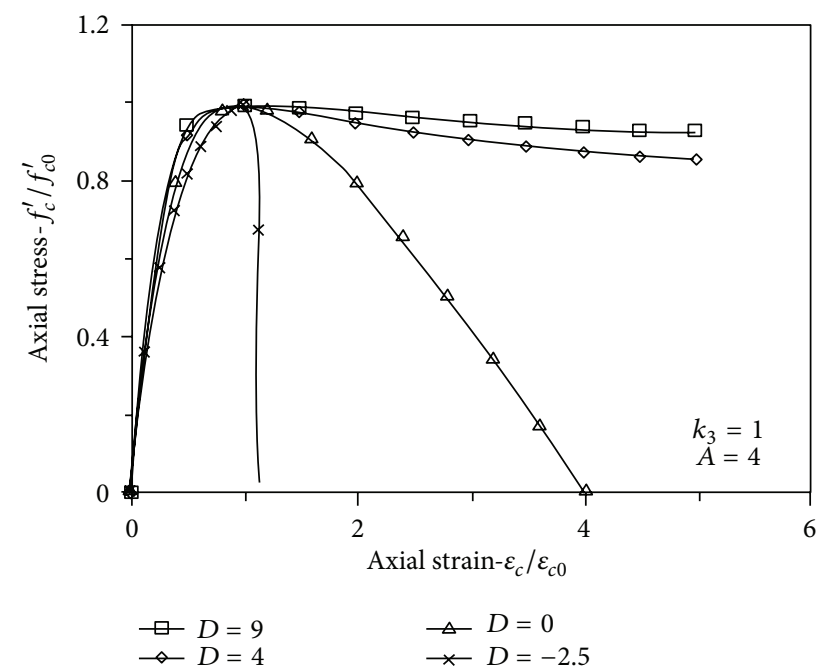

(b)

FIGURE 2: Variation of stress-strain relationship of Sargin [13] with the variation in the $A$ and $D$ parameters.

\section{Modified Sargin's Model for Lightly and Heavily Confined Concrete}

Several attempts of extending Sargin's model for steelconfined concrete to FRP-confined concrete were formulated [17-22], but none of them succeeded in obtaining a general model, able to represent with a unique analytical expression in all the deformation range of the behavior of both lightly or heavily confined concrete. To reach this aim, let us firstly summarize the procedure by which Sargin's analytical expression has been derived and discuss its analytical properties.

3.1. Sargin's Model. Sargin's model [13] was formulated for reproducing the stress-strain curve of concrete confined with steel reinforcements under axial compression. The curve is characterized by the attainment of the peak strength at the yielding of the transversal reinforcement, with consequent vanishing tangent elasticity modulus. The postpeak region is characterized by a falling branch, with variable slopes that depend on the confining pressure furnished by the transversal steel reinforcements. Sargin proposed to model such a behavior by the following simple analytical expression:

$$
\frac{f_{c}}{f_{c 0}}=k_{3} \frac{\bar{A} x+(\bar{D}-1) x^{2}}{1+(\bar{A}-2) x+\bar{D} x^{2}},
$$

where $f_{c 0}^{\prime}$ is the strength and $\varepsilon_{c 0}$ is the corresponding strain for the unconfined concrete, $x=\varepsilon_{c} / \varepsilon_{c 0}$ is the normalized strain, $A=E_{c} / E_{\mathrm{sec}}=\left(E_{c} \varepsilon_{c 0}\right) /\left(k_{3} f_{c 0}^{\prime}\right)=E_{c} /\left(k_{3} E_{\mathrm{sec} 0}\right)$ are the initial modulus of elasticity $E_{c}$ normalized with respect to the confined concrete secant modulus $E_{\mathrm{sec}}$ at the strain value $\varepsilon_{c 0}, k_{3}=f_{c c}^{\prime} / f_{c 0}^{\prime}$ is the normalized stress of the confined concrete at the strain $\varepsilon_{c 0}$, and $D$ is a parameter which affects mainly the slope of the softening branch. Equation (3) has been derived by approximating the results of experimental tests by the following general expressions:

$$
f_{c}^{\prime}=\frac{a+b x+c x^{2}}{1+d x+e x^{2}} .
$$

If the boundary conditions

$$
\begin{gathered}
f_{c}^{\prime}=0 \quad \text { at } \varepsilon=0, \\
\left.\frac{d f_{c}^{\prime}}{d \varepsilon}\right|_{\varepsilon=0}=E_{c}, \\
f_{c}^{\prime}=k_{3} f_{c 0}^{\prime} \quad \text { at } \varepsilon=\varepsilon_{c 0}, \\
\left.\frac{d f_{c}^{\prime}}{d \varepsilon}\right|_{\varepsilon=\varepsilon_{c 0}}=0
\end{gathered}
$$

are substituted, (4) is reduced to (3). While $k_{3}$ is a scaling parameter that reflects the increment of the maximum strength due to the confining reinforcement (often set equal to the unity in Sargin's papers), the variation of the parameters $A$ and $D$ generates different shapes of the stress-strain relationship. Higher values of $A$ give greater nonlinearity to the constitutive law in the pre-peak region; higher values of $\bar{D}$ represent more ductile behavior up to collapse. La Mendola and Papia [29] stressed that in order to make (3) physically admissible, the curve must not change its concavity in the range $0 \leq x \leq 1$; to this aim, the parameters $A$ and $D$ must be defined in the ranges $1-A \leq D \leq(A-1)^{2}$. If $A=1$ and $D=0$ are set, (3) represent Hooke's law $f_{c}^{\prime} / f_{c 0}^{\prime}=k_{3} \varepsilon_{c} / \varepsilon_{c 0}$; if $A=2$ and $D=0$ (3) are reduced to Hognestad's parabola for the unconfined concrete, while if $D$ leads to $\infty$, the rigidplastic behavior $f_{c}^{\prime} / f_{c 0}^{\prime}=k_{3}$ is obtained. Intermediate values of $D$ allow one to reproduce the behavior of elements with variable amount of confining reinforcement. In Figure 2, the curves obtained varying the parameters $A$ and $D$ are 
shown. In details, $D=(A-1)^{2}$ and $A=4$ have been assumed in Figure 2(a) and Figure 2(b), respectively. All curves show the ability of Sargin model to reproduce several softening shapes. In relation to the values of the parameters $A$ and $D$, (3) can be affected by singularities for one or two distinct values of $x$; it can be demonstrated that this occurrence is not physically meaningful because it may occur only for $x<0$, or when $D<1$ for an $x$ value greater than the strain value at which the curve intersects the strain reference axis. Let us stress that, due to the boundary condition (6b) imposed for reducing (4) to (3), Sargin's model is not able to represent the hardening behavior of elements heavily confined with FRP jackets.

3.2. Modified Sargin's Model. To the aim of obtaining an analytical expression able to represent the behavior of concrete with both hardening and softening behavior, the order of the numerator of (4) is increased up to the third order, obtaining the following general expression for the normalized stressstrain relationship:

$$
\frac{f_{c}^{\prime}}{f_{c 0}}=\frac{a+b x+c x^{2}+d x^{3}}{1+f x+g x^{2}} .
$$

The coefficients in (7) are now derived, as done by Sargin, by imposing the boundary condition; to this aim, three characteristic points of the stress-strain relationship are considered, namely, the normalized strain axis origin $x=0$, the normalized strain value at which the unconfined concrete reaches its peak strength $x=1$, and the collapse normalized strain of the confined concrete $x=x_{u}$. Let us emphasize that the stress and the tangent elasticity modulus at these strain characteristic values are able to characterize the behavior of the confined concrete in all the strain range.

When the element is not loaded, that is, $x=0$, the influence of the confining FRP jacket on the concrete stiffness is negligible, and the elasticity modulus of the confined and unconfined concrete are almost coincident. The experimental evidence shows also that the confining FRP or FRCM jacket is not able to significantly affect the concrete behavior; before that the transversal deformation has produced the cracking of the concrete [23], that is, when $x<1$. At the end of this first branch, the FRP or FRCM jacket-confining action became effective, and the stress-strain curve slope is determined by the transversal concrete to confining jacket relative stiffness; therefore the tangent elasticity modulus for $x=1$ is related to the effective stiffness of the confining system. Lastly, stress, strain, and elasticity modulus at the ultimate condition provide the necessary information on the strength and strain capacity of the confined members at the collapse, taking into account the mechanism that activates the failure.

Thus, the six coefficients appearing in (7) are determined by imposing the boundary conditions at the previously mentioned three characteristic points by means of the following procedure:

(i) firstly, the four coefficients $a, c, d$, and $g$ are evaluated, as functions of the other two parameters $b$ and $f$, by imposing following conditions:

$$
\begin{gathered}
f_{c}^{\prime}=0 \quad \text { at } x=\varepsilon=0, \\
\frac{f_{c}^{\prime}}{f_{c 0}^{\prime}}=k_{0} \quad \text { at } x=\frac{\varepsilon_{c 0}}{\varepsilon_{c 0}}=1, \\
\left.\frac{d f_{c}^{\prime}}{d \varepsilon}\right|_{\varepsilon=\varepsilon_{c 0}}=A_{0} E_{\sec 0} \quad \text { at } x=\frac{\varepsilon_{c 0}}{\varepsilon_{c 0}}=1, \\
\frac{f_{c}^{\prime}}{f_{c 0}^{\prime}}=k_{u} \quad \text { at } x=\frac{\varepsilon_{c u}}{\varepsilon_{c 0}}=x_{u},
\end{gathered}
$$

where $k_{1}$ and $k_{u}$ are the normalized strength of the confined concrete at the strain $\varepsilon_{c 0}$ and at the failure, and $A_{0}$ is the tangent elasticity modulus at the strain $\varepsilon_{c 0}$ of the confined concrete, normalized with respect to the correspondent secant elasticity modulus of the unconfined concrete $E_{\sec 0}$. Thus, $a=0$, and the three following expressions of the coefficients $c=c(b, f)$, $d=d(b, f)$, and $g=g(b, f)$ are obtained:

$$
\begin{aligned}
& c(b, f) \\
& =\frac{2 b k_{u} x_{u}^{2}+(f+2) k_{0}^{2} x_{u}^{3}}{x_{u}^{2}\left[\left(x_{u}-1\right) A_{0}+k_{0}-k_{u}\right]} \\
& \quad+\frac{A_{0}\left(x_{u}-1\right)\left[k_{u}\left(1+x_{u}+f x_{u}\right)-b x_{u}\left(x_{u}+1\right)\right]}{x_{u}^{2}\left[\left(x_{u}-1\right) A_{0}+k_{0}-k_{u}\right]} \\
& \quad+\frac{k_{0}\left[k_{u}\left(1+f x_{u}-3 x_{u}^{2}-2 f x_{u}^{2}\right)-b x_{u}\left(x_{u}^{2}+1\right)\right]}{x_{u}^{2}\left[\left(x_{u}-1\right) A_{0}+k_{0}-k_{u}\right]},
\end{aligned}
$$

$$
\begin{aligned}
& d(b, f) \\
& =\frac{\left[b-(f+2) k_{0}\right]\left(k_{0}-k_{u}\right) x_{u}^{2}}{x_{u}^{2}\left[\left(x_{u}-1\right) A_{0}+k_{0}-k_{u}\right]} \\
& \quad+\frac{-A_{0}\left(x_{u}-1\right)\left[k_{u}\left(1+x_{u}+f x_{u}\right)-b x_{u}\right]}{x_{u}^{2}\left[\left(x_{u}-1\right) A_{0}+k_{0}-k_{u}\right]},
\end{aligned}
$$

$$
\begin{aligned}
& g(b, f) \\
& =\frac{k_{u}+f k_{u} x_{u}-x_{u} b\left(x_{u}-1\right)^{2}}{x_{u}^{2}\left[\left(x_{u}-1\right) A_{0}+k_{0}-k_{u}\right]} \\
& \quad+\frac{-x_{u}^{2}\left[A_{0}(f+1)\left(x_{u}-1\right)+k_{0}\left(3+2 f-2 x_{u}-f x_{u}\right)\right]}{x_{u}^{2}\left[\left(x_{u}-1\right) A_{0}+k_{0}-k_{u}\right]},
\end{aligned}
$$

(ii) then, the expressions of the two $b$ and $f$ coefficients are obtained by imposing that the stress-strain curve has prefixed values of the normalized tangent elasticity modulus $A$ and $A_{\mathcal{u}}$ at the axis origin and the failure condition, respectively. Thus, (9) through (11) are substituted in (7), and the following boundary conditions are imposed:

$$
\left.\frac{d f_{c}^{\prime}}{d \varepsilon}\right|_{\varepsilon=0}=A E_{\mathrm{sec} 0},\left.\quad \frac{d f_{c}^{\prime}}{d \varepsilon}\right|_{\varepsilon=\varepsilon_{c u}}=A_{u} E_{\mathrm{sec} 0},
$$




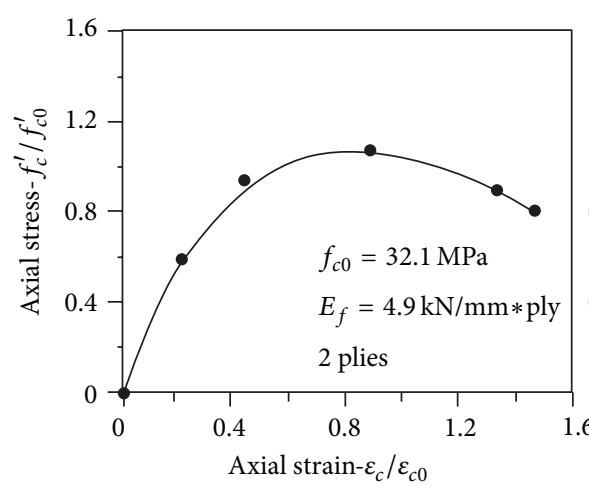

(a1)

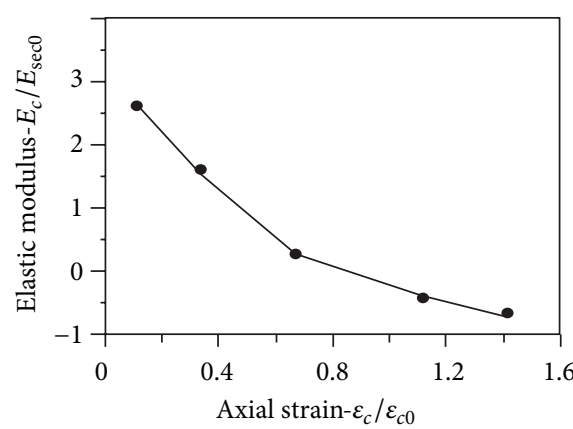

- Experimental SAm

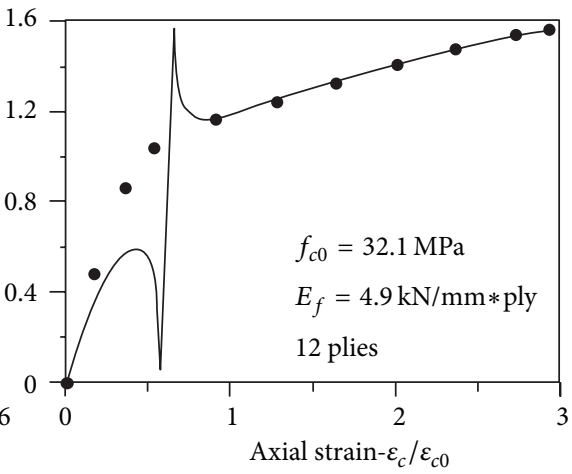

(b1)

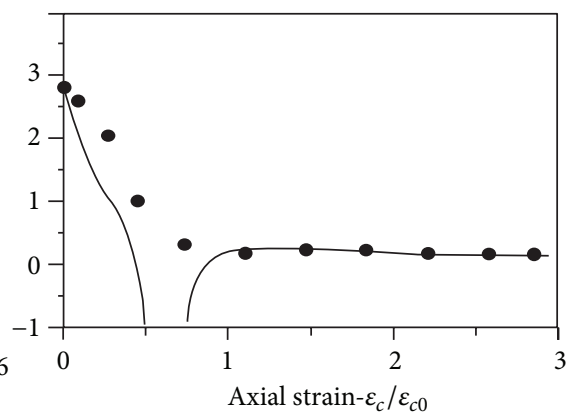

- Experimental SAm

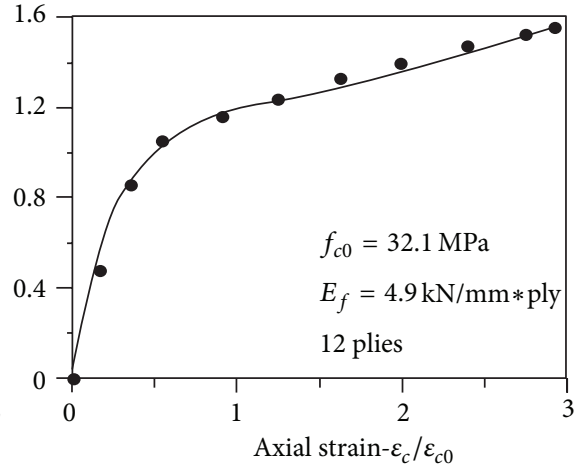

(c1)

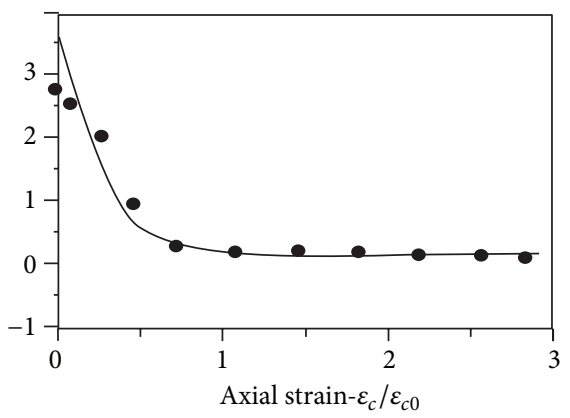

- Experimental SAm (a2) (b2)

(c2)

FIGURE 3: Accuracy of modified Sargin's model (SAm): $\bullet \bullet \bullet$ experimental curve; — SAm model.

and the following explicit expressions of the $b$ and $f$ coefficients are obtained:

$$
\begin{gathered}
b=A, \\
f=\frac{\left\{\begin{array}{c}
\left.A x_{u}\left[k_{u}+x_{u}^{2}\left(A_{u}-2 x_{u}-k_{u}+A_{u} x_{u}\right)\right]\right\} \\
-2 k_{u}^{2}-2 k_{0}^{2} x_{u}^{3}
\end{array}\right\}}{x_{u}^{2}\left\{\begin{array}{c}
\left.k_{u}^{2}+k_{0}^{2} x_{u}^{2}+A_{0}\left(x_{u}-1\right)^{2}\left(k_{u}-A_{u} x_{u}\right)\right\} \\
\left.-k_{0}\left[k_{u}\left(x_{u}^{2}+1\right)-A_{u} x_{u}\left(x_{u}-1\right)^{2}\right]\right\}
\end{array}\right.} \\
+\frac{A_{0}\left(x_{u}-1\right)^{2}\left\{\begin{array}{c}
x_{u}\left[A+A_{u}\left(1+x_{u}\right)\right] \\
-k_{u}\left(x_{u}+2\right)
\end{array}\right\}}{x_{u}^{2}\left\{\begin{array}{c}
\left.k_{u}^{2}+k_{0}^{2} x_{u}^{2}+A_{0}\left(x_{u}-1\right)^{2}\left(k_{u}-A_{u} x_{u}\right)\right\} \\
-k_{0}\left[k_{u}\left(x_{u}^{2}+1\right)-A_{u} x_{u}\left(x_{u}-1\right)^{2}\right]
\end{array}\right\}} \\
+\frac{k_{0}\left\{\begin{array}{c}
x_{u}\left(x_{u}-1\right)\left[A\left(1+x_{u}\right)+A_{u}\left(1+x_{u}-2 x_{u}^{2}\right)\right] \\
+2 k_{u}\left(1+x_{u}^{3}\right)
\end{array}\right\}}{x_{u}^{2}\left\{\begin{array}{c}
k_{u}^{2}+k_{0}^{2} x_{u}^{2}+A_{0}\left(x_{u}-1\right)^{2}\left(k_{u}-A_{u} x_{u}\right) \\
-k_{0}\left[k_{u}\left(x_{u}^{2}+1\right)-A_{u} x_{u}\left(x_{u}-1\right)^{2}\right]
\end{array}\right\}} .
\end{gathered}
$$

Once the values of the $b$ and $f$ coefficients obtained by (13) and (14) are introduced in (9) through (11), all the six coefficients of the modified Sargin (SAm) stress-strain relationship are obtained in explicit form, as functions of the stress and tangent elasticity modulus values at the three characteristic strain values $\varepsilon=0, \varepsilon=\varepsilon_{0}$, and $\varepsilon=\varepsilon_{u}$.
In most of the cases, the curves obtained by introducing the six values of the coefficients obtained by (9)-(11), (13) and (14) in (7) are able to represent the behavior of the FRP- or FRCM-confined concrete with large accuracy, as it is shown in Figures 3(a1) and 3(a2), where the normalized stress-strain and the normalized tangent elasticity modulus versus axial strain curves obtained by an experimental test [8] are compared with those provided by the modified Sargin model, where the parameter values $k_{1}, k_{u}, A, A_{0}, A_{u}, x_{u}$ are evaluated by means of the results of the test itself. Unluckily, two circumstances can make the coefficient values obtained by (13) and (14) unsuitable for uses in the modified Sargin model: (a) the stress-strain relationship is affected by one or two singularities for $x$ values that are comprised in the range $\left[0, x_{u}\right]$; (b) the correspondent curve of the tangent elasticity modulus exhibits a maximum in the range $0<x<1$, that is, the stress-strain curve changes its concavity in the same range. It can be demonstrated that the first circumstance occurs if one of the following conditions hold:

$$
\begin{gathered}
f^{2}>4 g \notin\left[0 \leq g \leq \frac{1}{x_{u}^{2}} \cap-\frac{1}{x_{u}}-g x_{u} \leq f \leq-2 g x_{u}\right] \\
\quad \text { for } g \geq 0, \\
-\frac{1}{x_{u}}-g x_{u} \leq f \leq-2 g x_{u} \quad \text { for } g<0 .
\end{gathered}
$$


Moreover, the stress-strain curve has to reproduces the loss of stiffness of the confined concrete in the first branch up to the strain $\varepsilon_{c 0}$, that is, the curve cannot change its concavity in the range $0<x<1$. Due to the condition imposed at the boundary of this interval, this circumstance is not verified if the second derivative at the origin is positive.

Therefore, the values of the three $b, c$, and $f$ coefficients derived by (11), (13), and (14) are also not suitable for the stress-strain law representation if they satisfy the following condition:

$$
\left.\frac{d^{2} f_{c}^{\prime}}{d \varepsilon^{2}}\right|_{\varepsilon=0}>0 \Longrightarrow b-c / f>0 .
$$

Thus, when at least one of (15), or (16) holds, a different procedure for determination of the coefficients $b$ and $f$ has to be considered, that solves the two previously mentioned drawbacks, by imposing that the two singularities of (7) are outside the range $\left[0, x_{u}\right]$, and the second derivative at the axis origin is not positive. To these aims, any stress-strain curve can be approximated by assuming that the second derivative vanishes at the axis origin, that is, (16) is satisfied as equalities.

Consider

$$
\left.\frac{d^{2} f_{c}^{\prime}}{d \varepsilon^{2}}\right|_{\varepsilon=0}=0 \Longrightarrow b(f)=\frac{\begin{array}{c}
A_{0} k_{u}\left(x_{u}-1\right)\left(1+x_{u}+f x_{u}\right) \\
+k_{0}\left[k_{0} x_{u}^{3}(2+f)+k_{u}\left(1+f x_{u}-3 x_{u}^{2}-2 f x_{u}^{2}\right)\right]
\end{array}}{x_{u}\left[\begin{array}{c}
\left(x_{u}-1\right)\left(1+x_{u}+f x_{u}\right) A_{0} \\
+k_{1}\left(1+x_{u}+f x_{u}^{2}\right)-k_{u} x_{u}(f+2)
\end{array}\right]} .
$$

The equation system (9), (10), (11), and (17) allows one to express the five coefficients $a=0, b, c, d$, and $g$ as functions of the characteristic stress-strain law parameters $k_{1}, k_{u}, x_{u}$, and $A_{0}$, and the sixth coefficient $f$, but none of the equations employed for their derivation imposes any condition on the derivatives at the axis origin and at the failure and on the deformation values for which (7) is affected by singularities. Therefore, the sixth condition is obtained by using the least square method in order to minimize the error in the representation of the tangent elasticity modulus at the axis origin and at the failure, with the condition that the singularities in (7) lie outside the stress interval $\left[0, x_{u}\right]$. Thus, the mean square error function is now defined as follows:

$$
\begin{aligned}
S_{2}(f)= & \left(\frac{\left.\left(1 / E_{\mathrm{sec} 0}\right)\left(d f_{c}^{\prime} / d \varepsilon\right)\right|_{x=0}-A}{A}\right)^{2} \\
& +\left(\frac{\left.\left(1 / E_{\mathrm{sec} 0}\right)\left(d f_{c}^{\prime} / d \varepsilon\right)\right|_{\varepsilon=\varepsilon_{u}}-A_{u}}{A_{u}}\right)^{2},
\end{aligned}
$$

and the $f$ value is determined by minimizing (18), satisfying also the following condition ensuring that any singularity lies in the interval $\left[0, x_{u}\right]$ :

$$
f>-\left(\frac{1}{x_{u}}+g(f) x_{u}\right)=-\left(1+\frac{1}{x_{u}}\right) .
$$

An explicit approximate solution for the least square method satisfying (19) can be obtained if the derivatives of (7) appearing in (18) are transformed in a linear form by a series expansion about the value $f_{A}$ for which (7) is affected by the target value $A$ of the elasticity modulus at the origin, and the solution is searched in the range $f>f_{A}$. It can be easily demonstrated that the latter condition implies that (19) is also satisfied and lead to the following approximate solution:

$$
f_{l}=f_{A}-\frac{m_{u} A^{2}\left(h_{u}-A_{u}\right)}{m^{2} A_{u}^{2}+m_{u}^{2} A^{2}}
$$

where

$$
\begin{gathered}
f_{A}=\frac{-A_{0}\left(x_{u}^{2}-1\right)\left(k_{u}-A x_{u}\right)-2 x_{u}^{2}\left(A k_{u}+k_{0}^{2} x_{u}\right)}{x_{u}\left[\begin{array}{c}
A k_{u} x_{u}+k_{0}^{2} x_{u}^{2}+A_{0}\left(x_{u}-1\right)\left(k_{u}-A x_{u}\right) \\
+k_{0}\left(k_{u}-A x_{u}-2 k_{u} x_{u}\right)
\end{array}\right]} \\
m=-\frac{\left[\begin{array}{c}
A k_{u} x_{u}+k_{0}^{2} x_{u}^{2}+A_{0}\left(x_{u}-1\right)\left(k_{u}-A x_{u}\right) \\
+k_{0}\left(k_{u}-A x_{u}-2 k_{u} x_{u}\right)
\end{array}\right]}{\left(A_{0}-k_{0}\right)\left(x_{u}-1\right)^{2}\left(k_{u}-k_{0} x_{u}\right)^{2}}, \\
m_{u}=-\frac{2\left[\begin{array}{c}
A k_{u} x_{u}+k_{0}^{2} x_{u}^{2}+A_{0}\left(x_{u}-1\right)\left(k_{u}-A x_{u}\right) \\
+k_{0}\left(k_{u}-A x_{u}-2 k_{u} x_{u}\right)
\end{array}\right]}{\left(A-k_{0}\right)^{3} x_{u}^{3}\left(A_{0}-k_{0}\right)\left(x_{u}-1\right)^{3}\left(k_{u}-k_{0} x_{u}\right)^{2}} \\
h_{u}=\frac{+A k_{u} x_{u}\left[\begin{array}{c}
A x_{u}\left(x_{u}+1\right)- \\
2 k_{u}
\end{array}\right]+k_{0}\left[\begin{array}{c}
k_{u}^{2}\left(3 x_{u}-1\right)-A^{2} x_{u}^{2}\left(x_{u}+1\right) \\
-2 A k_{u} x_{u}\left(x_{u}^{2}-1\right)
\end{array}\right]}{\left(A-k_{0}\right)^{2}\left(x_{u}-1\right) x_{u}^{3}}
\end{gathered}
$$

In Figures 3(b1) and 3(b2), it is shown a case [7] in which the representation of the stress-strain curve by SAm with coefficients evaluated by means of (9) through (11), (13) and (14) fails because a singularity is founded in the range $\left[0, x_{u}\right]$. Figures 3(c1) and 3(c2), where the coefficients evaluated by (9) through (11), (17) and (20) are employed, shows that the approximate solution also leading to reproduce both the stress-strain curve and the tangent elasticity modulus with great accuracy, with the only exception of the elastic modulus at very low strain values.

\section{Applications}

The effectiveness of the SAm model of transforming analysis design models, that require cumbersome incremental procedure, in handy equivalent design models is proved by comparison of the stress-strain curve carried out by the three models mentioned in Section 2: Spoelstra and Monti (SM) [26], Moran and Pantelides (MP) [25], and Samaan et al. (S) [23]. In order, to define different levels of confinement, the following notations are introduced for FRP- or FRCMconfined columns: $t=$ thickness of the reinforcing fiber, $D$ diameter of confined concrete core; $E_{f}$ the elastic modulus of the fiber, $\rho_{f}=4 t / D$; and $E_{l}=\rho_{f} E_{f} / 2, K_{l}=E_{l} / f_{c 0}^{\prime}$ the so-called "confinement modulus" of the FRP jacket. Three different values of the "confinement" modulus are considered, namely, $K_{l}=E_{l} / f_{c 0}^{\prime}=1.25,5,10$ and 15 . The SAm model coefficients are evaluated on the basis of the parameters 


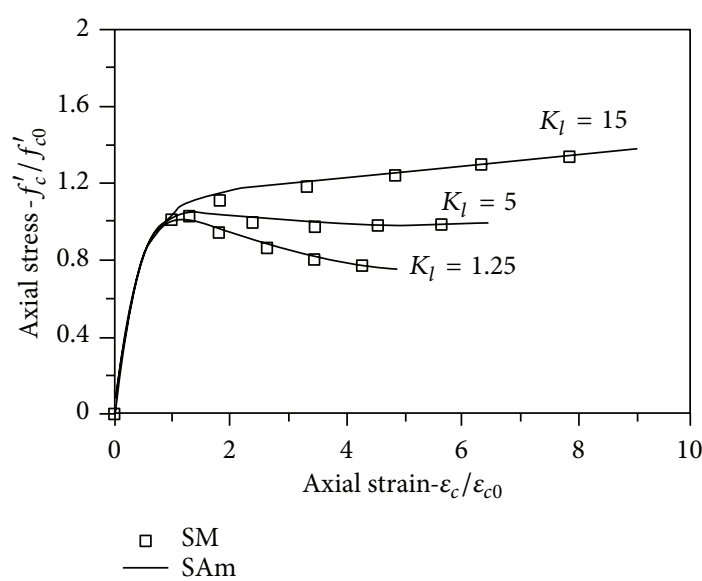

(a)

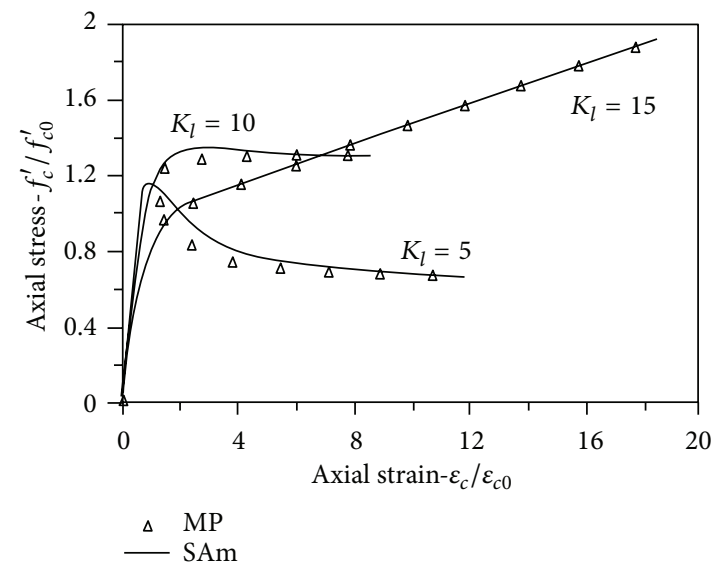

(b)

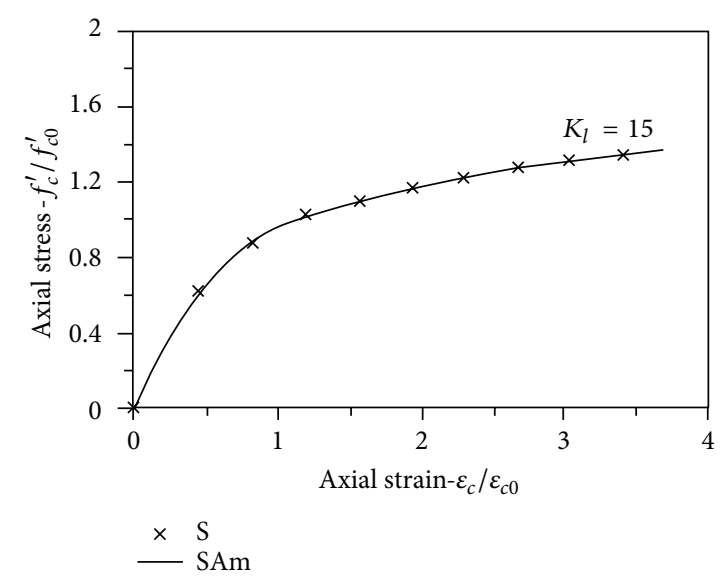

(c)

FIGURE 4: Stress-strain relationship: comparison of analytical results of Spoelstra and Monti [26] (a), Moran and Pantelides [25] (b), and Samaan et al. [23] (c) models with results of SAm.

provided by the same model that have to be approximated. The results shown in Figure 4 prove that the SAm model is able to reproduce the stress-strain curve for both very lightly confined $\left(K_{l}=1.25\right)$, lightly confined $\left(K_{l}=5\right)$, and heavily confined $\left(K_{l}=15\right)$ members.

Now it will be shown that, if the values of the parameters $A, k_{0}, A_{0}, x_{u}, k_{u}$ and $A_{u}$ are deduced from experimental tests, the model is able to accurately reproduce any experimental curve.

In Figure 5(a) through Figure 5(f), the stress-strain law deduced by experimental test performed by Harries and Kharel (HK) [8] for specimens having FRP jacket and concrete characteristics shown in Table 1 are compared with those obtained by the proposed model, while in Figure 6(a) through Figure 6(c), the same comparison is shown for the results of test performed by Shahawy et al. (SH) [7]. In Table 1, each specimen is identified by an acronym, in which the first two letters identify the author of experimental test (HK for a specimen tested by Harries and Kharel [8], $\mathrm{SH}$ for a specimen tested by Shahawy et al. [7], and the third identifies the type of the fiber ( $C$ for carbon fiber, $G$ for glass fiber)). The geometric and mechanic parameters of the reinforcing fiber and the concrete varies in wide ranges, such as the unconfined concrete strength (19.4, $33.5,49.0 \mathrm{MPa})$ or the fiber modulus (82700 MPa, 15700 $\mathrm{N} /\left[\mathrm{mm}^{*}\right.$ ply $\left.]\right)$ and the thickness of each fiber $(0.50 \div$ $3.00 \mathrm{~mm})$. Therefore, the stress-strain curves pertain to both lightly confined and heavily confined members. The curves show that, when the coefficients of the SAm are evaluated on the basis of the experimental tests, the model reproduces with very good accuracy the results of the experimental curve, even if the curve exhibits a decreasing branch at the high strain values (see Figures 5(a), 5(c), and 5(d)).

In order to evaluate numerically the effectiveness of the models in reproducing the experimental stress-strain curve, two performance indexes are defined as follows:

$$
\begin{aligned}
P_{i}= & \frac{\int_{\mathcal{\varepsilon}_{c 0}}^{\varepsilon_{c u}}\left[\operatorname{sign}\left(f_{c}^{\prime}-f_{c, \exp }^{\prime}\right)\right]^{i-1}\left(f_{c}^{\prime}-f_{c, \exp }^{\prime}\right) d \varepsilon}{\int_{\mathcal{\varepsilon}_{c 0}}^{\varepsilon_{c u}} f_{c, \exp }^{\prime} d \varepsilon} \\
& \times 100 \quad(i=1,2) .
\end{aligned}
$$




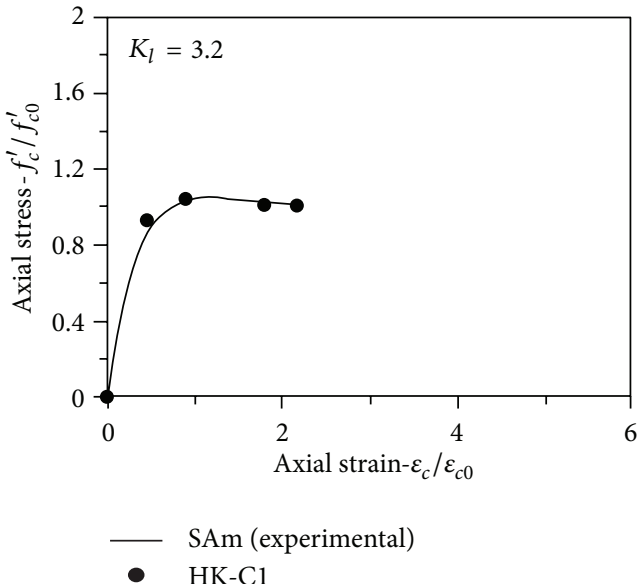

(a)

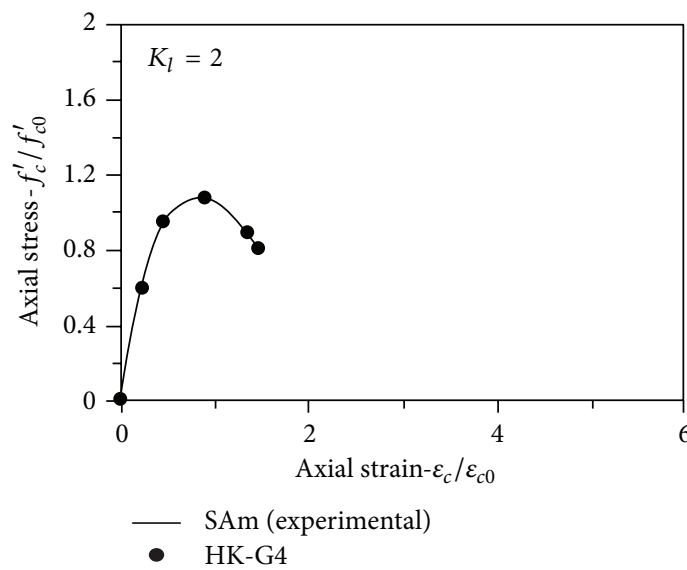

(c)

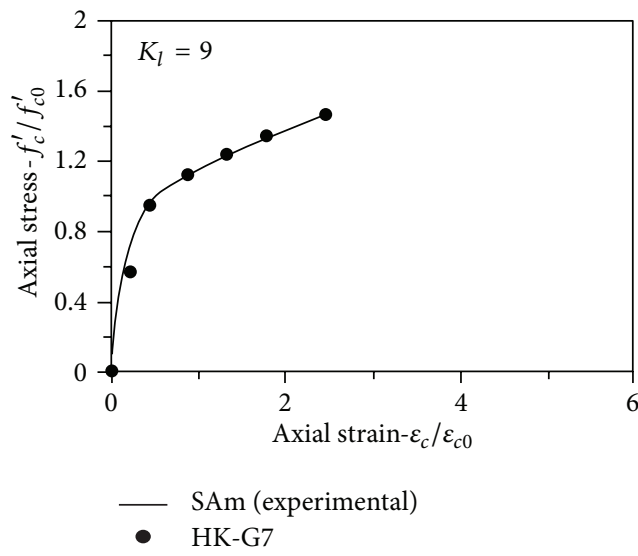

(e)

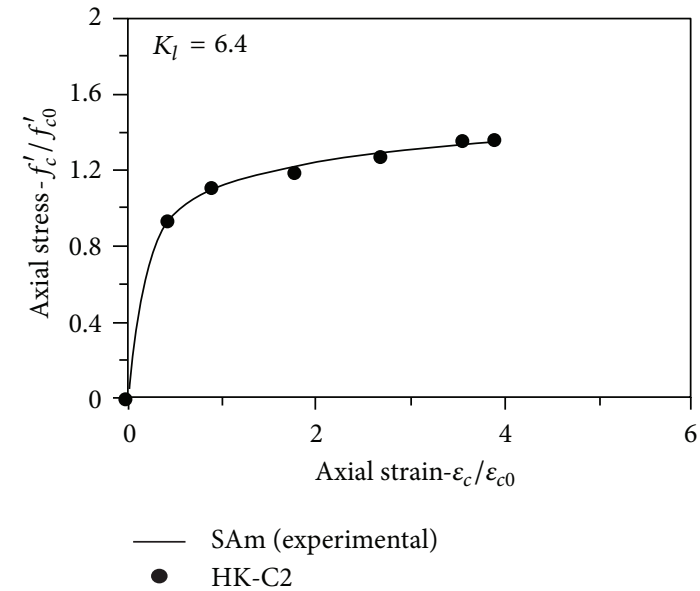

(b)

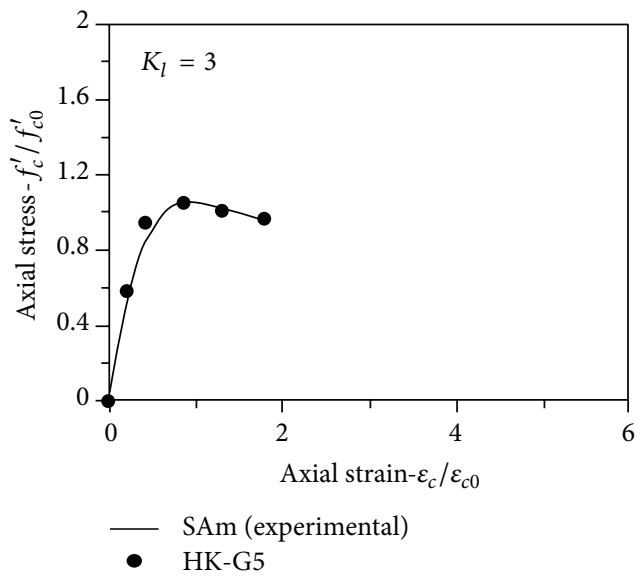

(d)

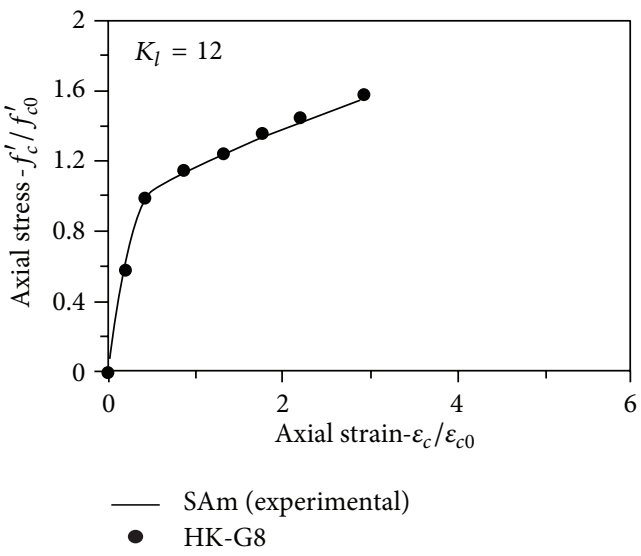

(f)

FIGURE 5: Stress-strain relationship: comparison of analytical results of Sargin's modified models (SAm) with experimental results.

In $(22), f_{c}^{\prime}$ is the stress value provided by the model, while $f_{c, \exp }^{\prime}$ and $\varepsilon_{c u \text {,exp }}$ are the stress and the ultimate strain of the experimental tests, and $\operatorname{sign}()$ is the function "signum." Therefore, $P_{1}$ measures the normalized integral of the error of the model in predicting the experimental stressstrain curve, while $P_{2}$ measures the normalized integral of the absolute value of the error of the model in predicting the experimental stress-strain curve. In Table 1, for each one of the 15 experimental tests considered, the values of indexes evaluated by the proposed SAm are shown, all the indexes for each specimen are close to zero, proving the effectiveness of the proposed model. 
TABLE 1: Mechanical and geometrical characteristics of specimens considered in Figures 5 and 6 and evaluation of error $P_{i}(\%)$ of SAm in prediction of curve $f_{c}^{\prime}-\varepsilon_{c}$ with experimental data.

\begin{tabular}{|c|c|c|c|c|c|c|}
\hline Code & $\begin{array}{c}f_{f} \\
\mathrm{~N} / \mathrm{mm} * \text { ply }\end{array}$ & $\begin{array}{c}E_{f} \\
\mathrm{kN} / \mathrm{mm} * \text { ply }\end{array}$ & plies & $K_{l}$ & $P_{1}(\%)$ & $P_{2}(\%)$ \\
\hline $\mathrm{HK}-\mathrm{Cl}$ & 174 & 15.7 & 1 & 3.2 & -0.3 & 0.3 \\
\hline HK-C2 & 174 & 15.7 & 2 & 6.4 & 1.7 & 1.7 \\
\hline HK-G4 & 75 & 4.9 & 2 & 2.0 & 0.0 & 0.0 \\
\hline HK-G5 & 75 & 4.9 & 3 & 3.0 & -0.2 & 0.2 \\
\hline HK-G6 & 75 & 4.9 & 6 & 6.0 & 0.5 & 0.5 \\
\hline HK-G7 & 75 & 4.9 & 9 & 9.0 & -0.7 & 0.8 \\
\hline HK-G8 & 75 & 4.9 & 12 & 12.0 & -1.1 & 1.1 \\
\hline Code & $\begin{array}{c}f_{f} \\
\mathrm{MPa}\end{array}$ & $\begin{array}{c}E_{f} \\
\mathrm{GPa}\end{array}$ & $\begin{array}{c}t_{f} \\
\mathrm{~mm}\end{array}$ & $K_{l}$ & $P_{1}(\%)$ & $P_{2}(\%)$ \\
\hline SH-C4 & 2275 & 82.7 & 2.5 & 69.3 & -1.8 & 1.8 \\
\hline $\mathrm{SH}-\mathrm{C} 5$ & 2275 & 82.7 & 1.0 & 11.1 & 2.1 & 2.1 \\
\hline SH-C6 & 2275 & 82.7 & 1.5 & 16.6 & 2.7 & 2.7 \\
\hline Mean & & & & & -0.6 & 2.1 \\
\hline
\end{tabular}

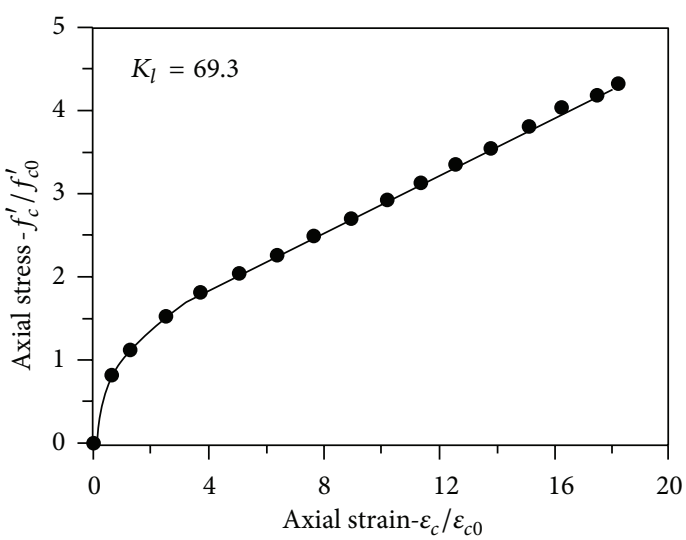

- SAm (experimental)

- $\mathrm{SH}-\mathrm{C} 4$

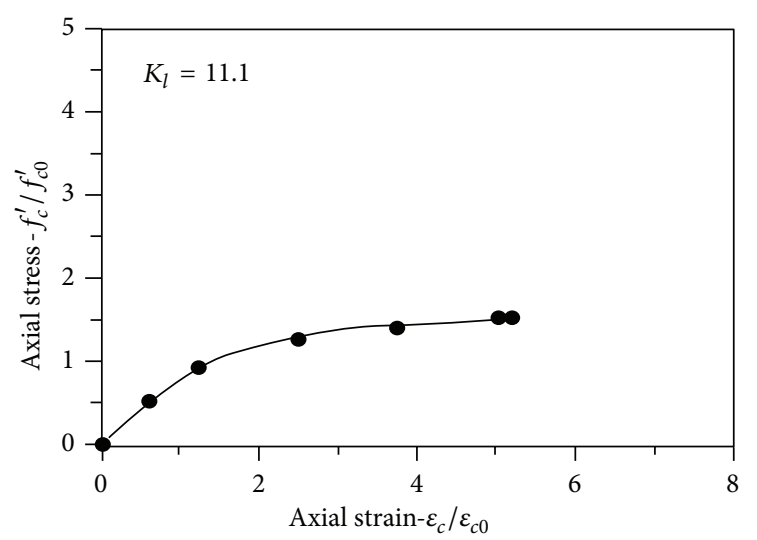

- SAm (experimental)

- $\mathrm{SH}-\mathrm{C} 5$

(a)

(b)

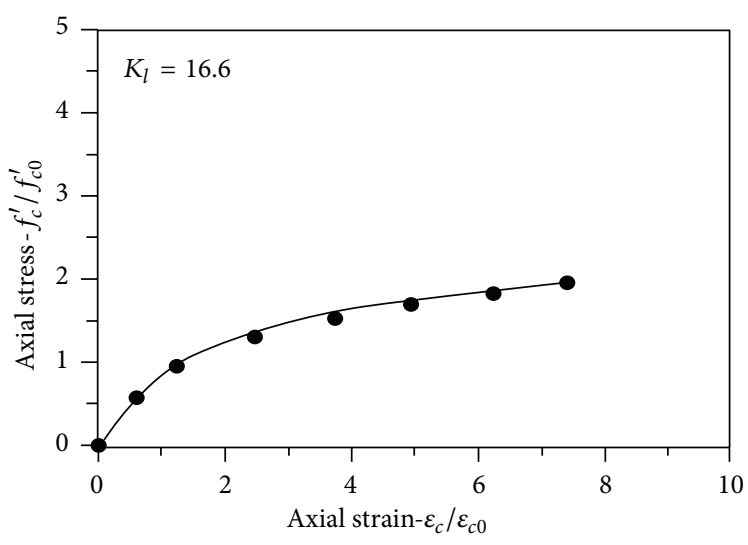

- SAm (experimental)

- $\mathrm{SH}-\mathrm{C6}$

(c)

FIGURE 6: Stress-strain relationship: comparison of analytical results of Sargin's modified models (SAm) with experimental results. 


\section{Conclusions}

By modification of the well-know Sargin's stress-strain relationship, a new law for representation of the constitutive behavior of FRP-confined members by a simple direct analytical expression has been proposed. The analytical model is able to reproduce the behavior of both very lightly confined members with softening behavior and heavily confined members with hardening behavior with accuracy greater than those of the most popular iterative analysis-oriented models available in literature. The numerical coefficients that characterize the model have been expressed by direct analytical relation as a function of the stress and the tangent elasticity modulus in three characteristic point of the stress-strain curves. Therefore, they can be easily evaluated either on the basis of experimental tests or by an analysis-oriented model that can now be represented by the proposed relationship, in order to obtain a unique general reliable law for every level of confinement.

\section{References}

[1] G. Campione, P. Colajanni, L. La Mendola, and N. Spinella, "Ductility of reinforced concrete members externally wrapped with fiber-reinforced polymer sheets," Journal of Composites for Construction, vol. 11, no. 3, pp. 279-290, 2007.

[2] G. Campione and M. Fossetti, "Compressive behaviour of concrete elliptical columns confined by single hoops," Engineering Structures, vol. 29, no. 3, pp. 408-417, 2007.

[3] L. Lam and J. G. Teng, "Design-oriented stress-strain model for FRP-confined concrete," Construction and Building Materials, vol. 17, no. 6-7, pp. 471-489, 2003.

[4] P. Colajanni, F. De Domenico, A. Recupero, and N. Spinella, "Elementi in calcestruzzo confinati con FRCM: analisi sperimentale per carichi monotonici," in Proceedings of the Associazione Italiana Cemento Armato e Precompresso, pp. 19-21, 2001.

[5] P. Colajanni, F. Di Trapani, G. Macaluso, M. Fossetti, and M. Papia, "Cyclic axial testing of columns confined with fiber reinforced cementitiuos matrix," in Proceedings of the 6th International Conference on FRP Composites in Civil Engineering (CICE '12), Roma, Italy, June 2012.

[6] P. Colajanni, F. De Domenico, N. Maugeri, A. Recupero, N. Spinella, and G. Mantegazza, "Experimental results of $\mathrm{RC}$ columns strengthened with fibre reinforced cementitious mortars," in Proceedings of the $3 d$ International Conference on Concrete Repair, Rehabilitation and Retrofitting, Cape Town, South Africa, September 2012.

[7] M. Shahawy, A. Mirmiran, and T. Beitelman, "Tests and modeling of carbon-wrapped concrete columns," Composites Part B, vol. 31, no. 6-7, pp. 471-480, 2000.

[8] K. A. Harries and G. Kharel, "Experimental investigation of the behavior of variably confined concrete," Cement and Concrete Research, vol. 33, pp. 873-880, 2003.

[9] L. De Lorenzis and R. Tepfers, "Comparative study of models on confinement of concrete cylinders with fiber-reinforced polymer composites," Journal of Composites for Construction, vol. 7, no. 3, pp. 219-237, 2003.

[10] L. Lam and J. G. Teng, "Behaviour and modeling of fiber reinforced polymer-confined concrete," Journal of Structural Engineering, vol. 130, no. 11, pp. 1713-1723, 2004.
[11] L. A. Bisby, A. J. S. Dent, and M. F. Green, "Comparison of confinement models for fiber-reinforced polymer-wrapped concrete," ACI Structural Journal, vol. 102, no. 1, pp. 62-72, 2005.

[12] H. Saadatmanesh, M. R. Ehsani, and M. W. Li, "Strength and ductility of concrete columns externally reinforced with fiber composite straps," ACI Structural Journal, vol. 91, no. 4, pp. 434447, 1994.

[13] M. Sargin, Stress-Strain Relationship for Concrete and the Analysis of Structural Concrete Sections, Study 4, Solid Mechanics Division; University of Waterloo, Waterloo, Canada, 1971.

[14] R. M. Richard and B. J. Abbot, "Versatile elastic-plastic stressstrain formula," Journal of the Engineering Mechanics Division, vol. 101, no. 4, pp. 511-515, 1975.

[15] J. B. Mander, M. J. N. Priestley, and R. Park, "Theoretical stress-strain model for confined concrete," Journal of Structural Engineering, vol. 114, no. 8, pp. 1804-1826, 1988.

[16] S. Popovics, "Numerical approach to the complete stress-strain relation for concrete," Cement and Concrete Research, vol. 3, no. 5, pp. 583-599, 1973.

[17] S. H. Ahmad, A. R. Khaloo, and A. Irshaid, "Behaviour of concrete spirally confined by fibreglass Filament," Magazine of Concrete Research, vol. 43, no. 156, pp. 143-148, 1991.

[18] H. A. Toutanji, "Stress-strain characteristics of concrete columns externally confined with advanced fiber composite sheets," ACI Materials Journal, vol. 96, no. 3, pp. 397-404, 1999.

[19] M. Saafi, H. A. Toutanji, and Z. Li, "Behavior of concrete columns confined with fiber reinforced polymer tubes," $A C I$ Materials Journal, vol. 96, no. 4, pp. 500-509, 1999.

[20] K. Miyauchi, S. Nishibayashi, and S. Inoue, "Estimation of strengthening effects with carbon fiber sheet for concrete column," in Proceedings of the 3rd International Symposium (FRPRCS-3) on Non-Metallic (FRP) Reinforcement for Concrete Structures, vol. 1, pp. 217-224, Sapporo, Japan, 1997.

[21] D. Lillistone and C. K. Jolly, "An innovative form of reinforcement for concrete columns using advanced composites," Structural Engineer, vol. 78, no. 23-24, pp. 20-28, 2000.

[22] X. Jin, J. Pan, G. Liu, and W. Lai, "Research of stress-strain curve of concrete confined by fiber reinforced plastics under axial compression," Journal of Building Structures, vol. 24, no. 4, pp. 47-53, 2003.

[23] M. Samaan, A. Mirmiran, and M. Shahawy, "Model of concrete confined by fiber composites," Journal of Structural Engineering, vol. 124, no. 9, pp. 1025-1031, 1998.

[24] Y. Xiao and H. Wu, "Compressive behavior of concrete confined by various types of FRP composites jackets," Journal of Reinforced Plastics and Composites, vol. 22, no. 13, pp. 1187-1202, 2003.

[25] D. A. Moran and C. P. Pantelides, "Damage-based stress-strain model for fiber-reinforced polymer-confined concrete," ACI Structural Journal, vol. 102, no. 1, pp. 54-61, 2005.

[26] M. Spoelstra and G. Monti, "FRP-Confined concrete model," Journal of Composites for Construction, vol. 3, no. 3, pp. 143-150, 1999.

[27] A. Z. Fam and S. H. Rizkalla, "Confinement model for axially loaded concrete confined by circular fiber-reinforced polymer tubes," ACI Structural Journal, vol. 98, no. 4, pp. 451-461, 2001.

[28] K. A. Harries and G. Kharel, "Behavior and modeling of concrete subject to variable confining pressure," ACI Materials Journal, vol. 99, no. 2, pp. 180-189, 2002.

[29] L. La Mendola and M. Papia, "General stress-strain model for concrete or masonry response under uniaxial cyclic compression," Structural Engineering and Mechanics, vol. 14, no. 4, pp. 435-454, 2002. 

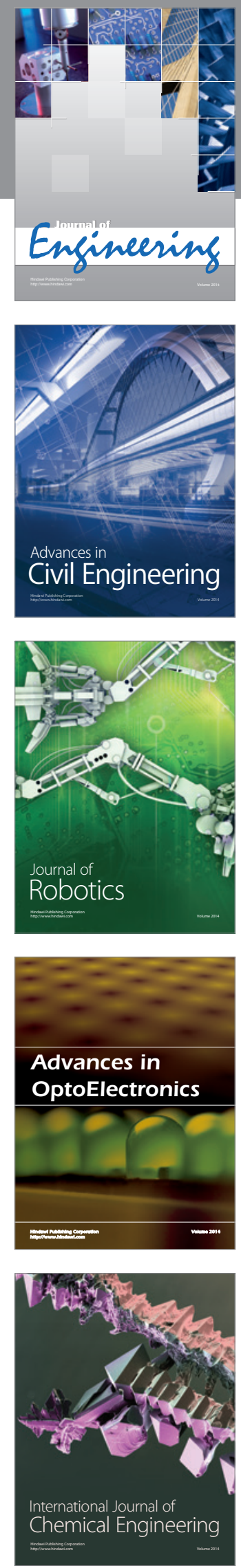

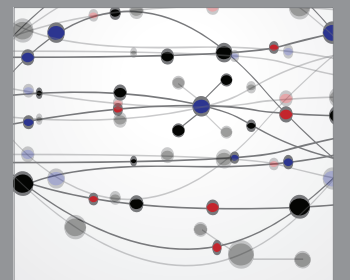

The Scientific World Journal
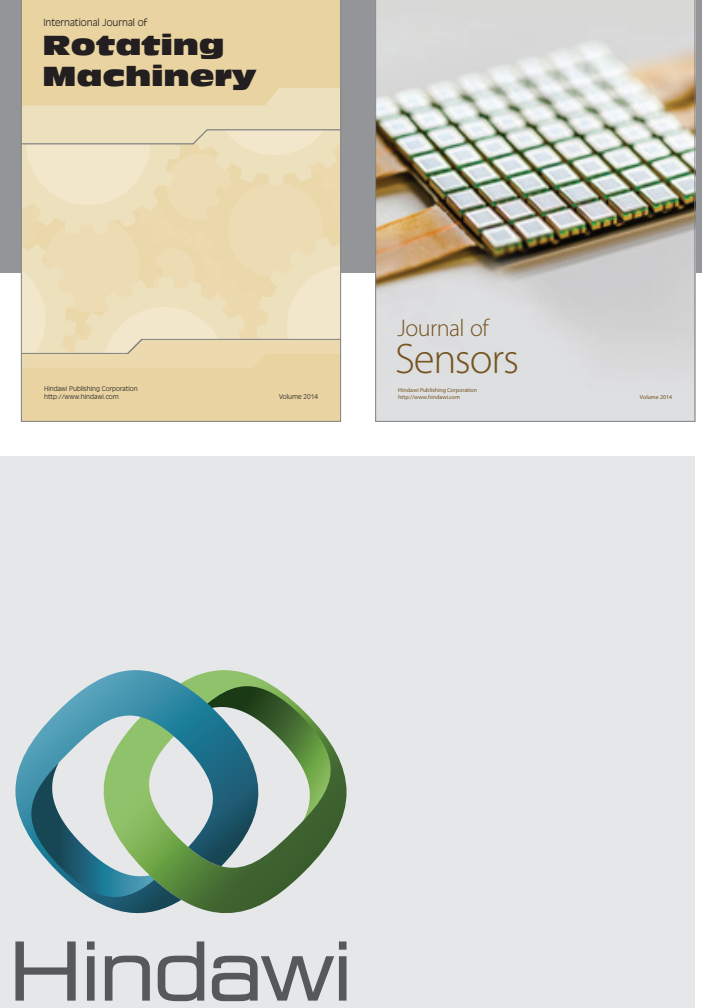

Submit your manuscripts at http://www.hindawi.com
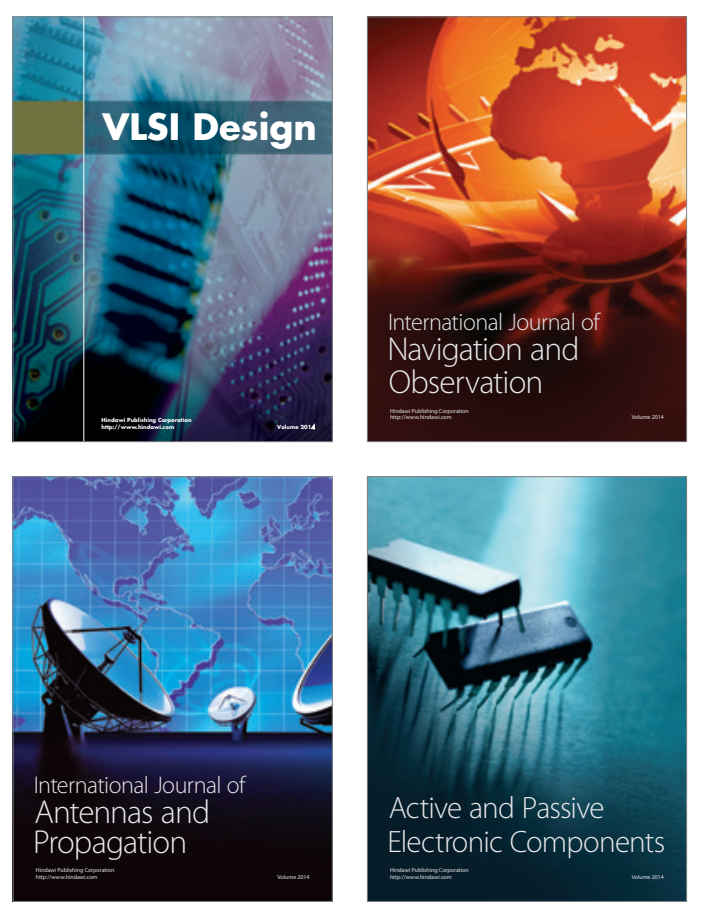
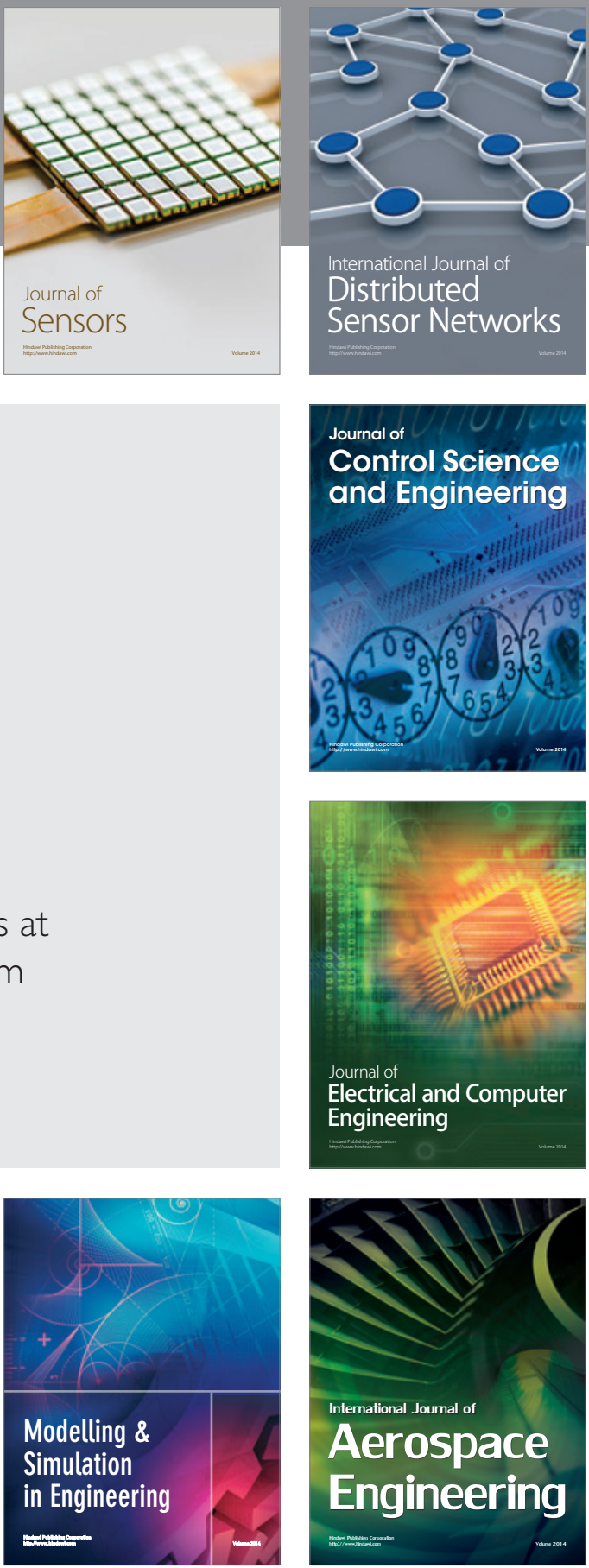

Journal of

Control Science

and Engineering
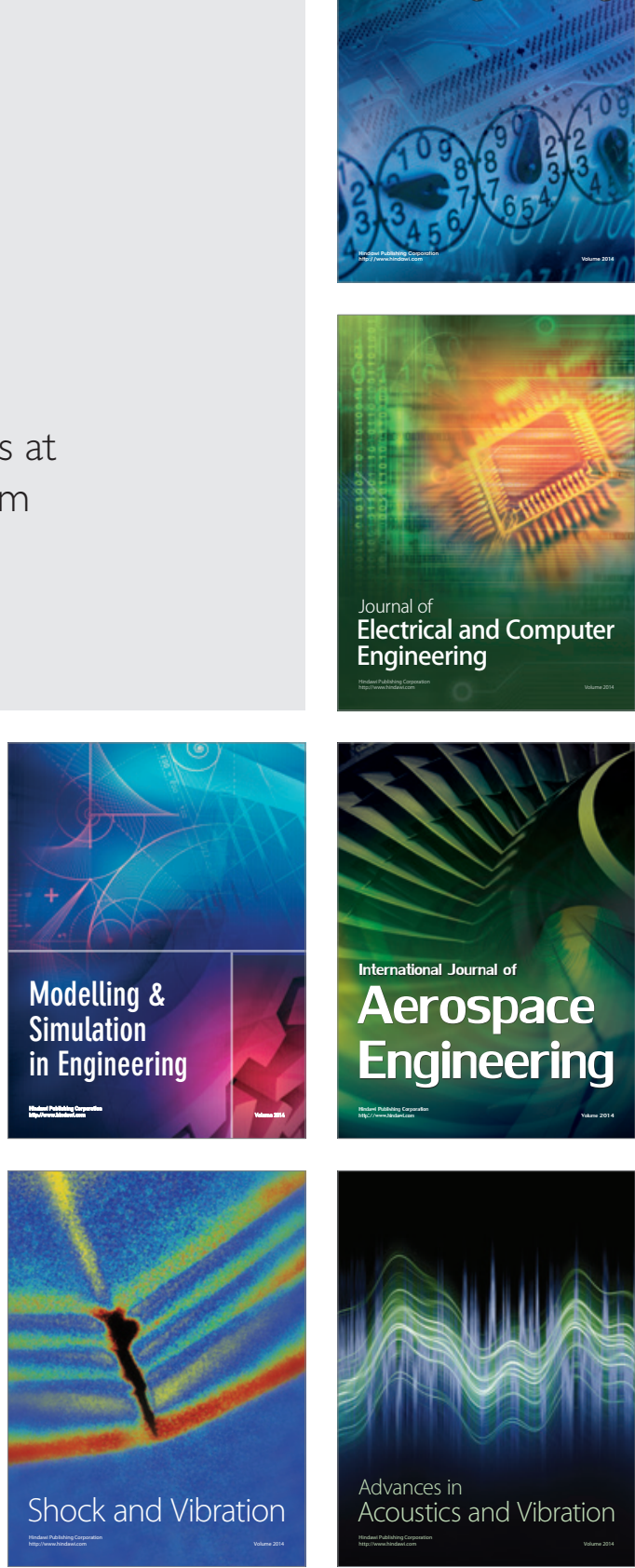